\title{
Multipoint determination of pressure-volume curves in human intervertebral discs
}

\author{
Harcharan Singh Ranu
}

\begin{abstract}
To gain further insight into the biomechanics of the human intervertebral disc and to determine a potential mechanism for causation and relief of symptoms related to a herniated disc, the pressure-volume relation was determined within the nucleus pulposus. Pressure was measured continuously within the nucleus pulposus in 17 intact lumbar discs from human cadavers by means of a miniature strain gauge at the tip of a size 4 French $(1.3 \mathrm{~mm})$ catheter inserted into the nucleus pulposus. The volume of the nucleus pulposus was increased at the slow, continuous rate of $0.034 \mathrm{ml} / \mathrm{min}$ by the pump regulated infusion of saline coloured with methylene blue. In 12 unloaded discs, nucleus pulposus pressure rose in a linear fashion (linear $r=0.96$ ) from an initial mean pressure of 174 (SD 81) $\mathrm{kPa}$. The mean rate of pressure rise was $327(\mathrm{SD} 109) \mathrm{kPa} / \mathrm{ml}$ volume increase. The peak pressure measured was $550 \mathrm{kPa}$; this was slightly higher than the capability of the transducer. Similar linear relations were obtained during infusion of saline into five vertically loaded discs fixed at the deformation produced by a $9.1 \mathrm{~kg}$ weight. The data define the pressure-volume relation within the disc and show that the nucleus pulposus, surrounded by the relatively inelastic annulus and the solid vertebral end plates, has the properties of a tight hydraulic space in which a large pressure rise will regularly result from a small increase in volume. Presumably the opposite is also true. The data may provide a biomechanical basis for the physiological variation in symptoms related to the disc, and for any benefit obtained from interventions designed to remove disc tissue.
\end{abstract}

(Ann Rheum Dis 1993; 52: 142-146)

Biomechanics,

New York College of Osteopathic Medicine of New York

Institute of Technology,

Old Westbury,

New York, 11568,

USA and

Department of Medicine,

St Luke's/Roosevelt

Hospital Medical Center,

Columbia University

College of Physicians

and Surgeons,

New York,

New York 10025,

USA

H S Ranu

Correspondence to:

Professor H S Ranu.

PO Box 199,

Greenvale,

New York 11548-0199.

USA

Accepted for publication

11 September 1992

in pressure to be expected within the nucleus pulposus if its intrinsic volume should be physiologically altered such as in the course of fluid absorption or loss. ${ }^{5}$ The findings could also serve as a basis for the beneficial clinical response seen after manoeuvres in which a portion of the nucleus pulposus is either dissolved (chymopapain), ${ }^{6}$ removed (percuta- neous nucleotome or surgery),,$^{7}$ or vapourised (percutaneous laser).. ${ }^{9} 10$

Nachemson found that the semigelatinous nucleus pulposus fulfilled one of the requirements of a hydraulic system in that pressure within it was equally transmitted in all directions. ${ }^{11}$ Ranu ${ }^{1213}$ reported that the fibrous nature of the laterally surrounding annulus was so strong that fracture of the vertebral end plates usually occurred before the annulus ruptured if extreme loads were applied to the cadaver spine in a longitudinal direction, or if the nucleus pulposus pressure was increased to extreme values by contrast injection. ${ }^{14}$ In pressure regulated injections of contrast into the human cervical nucleus pulposus in vivo at 1077 $\mathrm{kPa}(8000 \mathrm{~mm} \mathrm{Hg})$, not more than $0.3 \mathrm{ml}$ was injected unless the annulus had been ruptured. ${ }^{2}$ It has often been noted that extreme resistance is offered to an attempted injection of contrast into the nucleus pulposus, so that not more than 1 to $1.5 \mathrm{ml}$ can be injected by syringe. ${ }^{1}$

Thus it might be expected that pressure within the nucleus pulposus would reach extreme heights with application of a load to the vertebral column because pressure is not dissipated beyond the semi rigid annulus, and this has been found to be the case during life as well as in the cadaver. For example, pressure in the nucleus pulposus has been shown to increase by $450 \mathrm{kPa}$ from the supine to the sitting position ${ }^{4}$ and to reach $1900 \mathrm{kPa}$ if the person leans forward and holds a $20 \mathrm{~kg}$ weight in each hand. ${ }^{11}$ Intradiscal pressures of $3360 \mathrm{kPa}$ (25 $200 \mathrm{~mm} \mathrm{Hg}$ ) or more have been recorded in cadaver discs when loaded in compression to the point of fracture. ${ }^{15} 16$

The best way to obtain a complete evaluation of the mechanical capabilities and limitations of the human intervertebral disc, however, is to examine the continuous relation between pressure and volume within the nucleus pulposus. This curve will characterise the degree of rigidity of the nucleus pulposus/annulus system, the capacities of the disc, and the amount of pressure change in the nucleus pulposus to be expected for a given alteration in its volume.

In this study pressure was recorded continuously while increasing volume at a slow and constant rate by the regulated infusion of saline into the nucleus pulposus of human lumbar intervertebral discs obtained at necropsy.

\section{Materials and methods} vertebrae with the interposed intervertebral discs and longitudinal ligaments intact were
Within 24 hours of necropsy, human lumbar 
Table 1 Unloaded discs: rate of increase in intradiscal pressure with volume of infusion

\begin{tabular}{|c|c|c|c|c|c|c|c|}
\hline $\begin{array}{l}\text { Disc } \\
\text { No }\end{array}$ & $\begin{array}{l}\text { Rate of pressure } \\
\text { rise with } \\
\text { volume }(\mathrm{kPa} / \mathrm{ml})\end{array}$ & $\begin{array}{l}\text { Linear } \\
\text { correlation } \\
\left(r^{2}\right)\end{array}$ & $\begin{array}{l}\text { No of } \\
\text { data } \\
\text { points }\end{array}$ & $\begin{array}{l}\text { Initial } \\
\text { pressure } \\
(k P a)\end{array}$ & $\begin{array}{l}\text { Maximum } \\
\text { pressure } \\
(k P a)\end{array}$ & $\begin{array}{l}\text { ml in } \\
\text { at max } \\
\text { pressure }\end{array}$ & $\begin{array}{l}\text { Disc } \\
\text { class }\end{array}$ \\
\hline $\begin{array}{r}1 \\
2 \\
3 \\
4 \\
5 \\
6 \\
7 \\
8 \\
9 \\
10 \\
11 \\
12\end{array}$ & $\begin{array}{l}233 \\
173 \\
499 \\
205 \\
356 \\
322 \\
422 \\
546 \\
277 \\
296 \\
252 \\
339\end{array}$ & $\begin{array}{l}0.887 \\
0.663 \\
0.908 \\
0.940 \\
0.950 \\
0.989 \\
0.983 \\
0.950 \\
0.915 \\
0.989 \\
0.989 \\
0.992\end{array}$ & $\begin{array}{r}12 \\
14 \\
5 \\
22 \\
11 \\
20 \\
22 \\
11 \\
15 \\
28 \\
55 \\
33\end{array}$ & $\begin{array}{r}261 \\
262 \\
226 \\
39 \\
196 \\
109 \\
175 \\
292 \\
211 \\
55 \\
88 \\
179\end{array}$ & $\begin{array}{l}337 \\
382 \\
300 \\
173 \\
310 \\
321 \\
498 \\
488 \\
326 \\
332 \\
552 \\
545\end{array}$ & $\begin{array}{l}0.147 \\
0.487 \\
0.174 \\
0.765 \\
0.383 \\
0.696 \\
0.765 \\
0.383 \\
0.522 \\
0.974 \\
1.913 \\
1.148\end{array}$ & $\begin{array}{l}3 \\
3 \\
2 \\
1 \\
1 \\
2 \\
1 \\
1 \\
2 \\
3 \\
3 \\
2\end{array}$ \\
\hline $\begin{array}{l}\text { Mean } \\
\text { SD }\end{array}$ & $\begin{array}{l}327 \\
110\end{array}$ & $\begin{array}{l}0.930 \\
0.087\end{array}$ & $\begin{array}{l}21 \\
12 \cdot 8\end{array}$ & $\begin{array}{r}174 \\
81\end{array}$ & $\begin{array}{l}380 \\
111\end{array}$ & $\begin{array}{l}0.696 \\
0.467\end{array}$ & $\begin{array}{l}2 \cdot 0 \\
0.8\end{array}$ \\
\hline
\end{tabular}

removed and frozen at $-20^{\circ} \mathrm{C}$. The specimens were later thawed at room temperature for 18 hours and mounted vertically in a stabilising frame. Pressure within the nucleus pulposus was measured by the insertion of a 4 French $(1 \cdot 3 \mathrm{~mm}$ diameter), closed end catheter that contained a miniature pressure transducer close to the tip (Keller PSI, Oceanside, California). The transducer consisted of a micromachined chip and integrated circuitry with a self contained Wheatstone bridge. It was $5 \mathrm{~mm}$ long and mounted on the side of the catheter $1 \mathrm{~mm}$ from the tip, and did not increase the diameter of the catheter. The electrical connections for power and output voltage were carried in the catheter wall. The transducer thermal drift was 0.018 $\mathrm{kPa} /{ }^{\circ} \mathrm{C}$, a negligible value in relation to the pressure obtained. The studies were performed at room temperature. The transducer responded rapidly to changes in pressure, with a frequency response of $100 \mathrm{kHz}$. The maximum. pressure specified by the manufacturer for the gauge was 5 bar (506 kPa, $3800 \mathrm{~mm} \mathrm{Hg}$ ); however, it was capable of measuring slightly higher pressures (tables 1 and 2). It was calibrated with a compressed air system before each insertion into the disc and after its removal. The response of the transducer was linear over the range used.

For placement of the transducer into the nucleus pulposus, a 14 gauge trochar needle with a plastic sheath (Angiocath) was first inserted about $2 \mathrm{~cm}$ into the visible disc annulus posterolaterally, the trochar removed, the catheter inserted through the hub to $2 \mathrm{~mm}$ beyond the end of the plastic sheath, and the sheath withdrawn. This left the catheter tip near the centre of the nucleus pulposus. The catheter position outside the disc was rigidly fixed with an external support to prevent motion, as there was a tendency for the catheter to be forced out as the pressure in the nucleus pulposus rose. Rotation of the catheter, as well as withdrawal and reinsertion of the transducer into another site in the nucleus pulposus did not significantly change the pressure, as previously noted by others. ${ }^{17}$

The saline to be infused was coloured with methylene blue so as to detect any leak that may develop and to determine the actual site of injection and its distribution in the nucleus pulposus. In fact a slow and continuous rate of infusion prevents relaxation. Tissues that are viscoelastic in nature must be tested at a slower rather than a higher rate of response as the higher rate will show a linear response. A Harvard syringe pump with a worm gear was used for infusion, with the rate of infusion for each study set at a calibrated $0.034 \mathrm{ml} /$ minute. Tubing from the syringe was connected to a 22 gauge needle that had been inserted into the nucleus pulposus near its centre.

Pressure was recorded continuously at a speed of $50 \mathrm{~mm} / \mathrm{minute}$ on a direct writing oscillograph (Beckman) simultaneously on three channels set at high, medium, and low sensitivity so as to capture the earliest and the greatest pressure responses without altering the recording variables. Saline was infused continuously until the pressure approached the limits of the gauge ( 5 bar, $506 \mathrm{kPa}, 3800 \mathrm{~mm} \mathrm{Hg}$ ), or until there was evidence of a leak.

After the saline infusion, the discs were cut in half and rated according to the degree of degenerative disease on the gross scale of 1 to $4^{11}$; no discs graded 4 are included in these data. Discs were also discarded from analysis if there was any evidence of leakage; because of high pressures obtained, leakage was sometimes evident from the puncture sites through the annulus or into the vertebral end plates.

Data are also presented from similarly conducted pressure volume studies in five other discs that were subjected to a vertical loading before the infusion. They were clamped in a specially constructed frame. Pressure was initially recorded in the unloaded state as already described. Then a $9 \cdot 1 \mathrm{~kg}$ weight was placed on the vertical loading platform, four wing nuts were tightened to maintain the loaded dimension constant, and the weight was removed. The time lapse between applying the load of $9 \cdot 1 \mathrm{~kg}$ and tightening the wing nuts was two hours. The purpose of this part of the experiment was to test the response of the intervertebral disc to load and saline infusion at the same time. The load of $9 \cdot 1 \mathrm{~kg}$ is about one fourth of the load used by Nachemson. ${ }^{11}$ Thus a partial in vivo loading situation was simulated.

Table 2 Preloaded discs: rate of increase in intradiscal pressure with volume of infusion

\begin{tabular}{|c|c|c|c|c|c|c|c|c|}
\hline $\begin{array}{l}\text { Disc } \\
\text { No }\end{array}$ & $\begin{array}{l}\text { Rate of pressure } \\
\text { rise with } \\
\text { volume }(\mathrm{kPa} / \mathrm{ml})\end{array}$ & $\begin{array}{l}\text { Linear } \\
\text { correlation } \\
\left(r^{2}\right)\end{array}$ & $\begin{array}{l}\text { No of } \\
\text { data } \\
\text { points }\end{array}$ & $\begin{array}{l}\text { Initial } \\
\text { pressure } \\
(k P a)\end{array}$ & $\begin{array}{l}\text { Loaded } \\
\text { pressure } \\
\left(k P^{\prime} a\right)\end{array}$ & $\begin{array}{l}\text { Maximum } \\
\text { pressure } \\
\left(k P^{\prime} a\right)\end{array}$ & $\begin{array}{l}\text { ml in } \\
\text { at max } \\
\text { pressure }\end{array}$ & $\begin{array}{l}\text { Disc } \\
\text { class }\end{array}$ \\
\hline $\begin{array}{l}1 \\
2 \\
3 \\
4 \\
5\end{array}$ & $\begin{array}{l}184 \\
387 \\
197 \\
180 \\
140\end{array}$ & $\begin{array}{l}0.990 \\
0.956 \\
0.988 \\
0.992 \\
0.986\end{array}$ & $\begin{array}{l}56 \\
17 \\
44 \\
53 \\
66\end{array}$ & $\begin{array}{r}85 \\
226 \\
156 \\
92 \\
106\end{array}$ & $\begin{array}{l}198 \\
326 \\
248 \\
205 \\
212\end{array}$ & $\begin{array}{l}503 \\
545 \\
510 \\
510 \\
503\end{array}$ & $\begin{array}{l}1.948 \\
0.591 \\
1.530 \\
1.843 \\
2.296\end{array}$ & $\begin{array}{l}1 \\
1 \\
2 \\
1 \\
2\end{array}$ \\
\hline $\begin{array}{l}\text { Mean } \\
\text { SD }\end{array}$ & $\begin{array}{r}218 \\
87\end{array}$ & $\begin{array}{l}0.982 \\
0.013\end{array}$ & $\begin{array}{l}47 \\
17\end{array}$ & $\begin{array}{r}133 \\
53\end{array}$ & $\begin{array}{r}238 \\
47\end{array}$ & $\begin{array}{r}514 \\
16\end{array}$ & $\begin{array}{l}1.642 \\
0.579\end{array}$ & $\begin{array}{l}1.4 \\
0.49\end{array}$ \\
\hline
\end{tabular}


After stabilisation of pressure the saline infusion was started as described.

Pressure data were taken from the recording at one minute intervals, equivalent to a volume increase of $0.034 \mathrm{ml}$. The amount of fluid injected at any time could be accurately determined from the elapsed time on the recorder. Standard linear regression statistics were used to evaluate the relation between pressure and volume.

\section{Results}

UNLOADED DISCS

The initial pressure measured in the nucleus pulposus in these 12 discs (table 1) was very high compared with pressure measurements in other biological tissues; the mean initial nucleus pulposus pressure was $174 \mathrm{kPa}(1305 \mathrm{~mm} \mathrm{Hg})$, with a highest pressure value of $292 \mathrm{kPa}$. The initial pressure remained stable until saline infusion was begun.

Nucleus pulposus pressure rose rapidly and progressively during the continuous and constant rate saline infusion. Figure 1 presents data for five of the 12 discs studied to show the range of pressure changes (an average 21 data points per disc). A linear regression analysis was performed for each disc; there was a high degree of linear correlation between the volume infused and increase in pressure, with a correlation coefficient $(r)$ of 0.96 ; the mean $\mathrm{r}^{2}$ was 0.93 , indicating that $93 \%$ of the pressure change was related to the infusion. An unusually high degree of correlation was present, but examination of the point by point data (fig 1) shows that there was often a slower rate of pressure rise for the first 0.1 to $0.2 \mathrm{ml}$ infused. The maximum pressure achieved was necessarily limited by stopping the infusion near the stated capabilities of the pressure transducer or by the appearance of a leak of the saline (which contained a blue dye). The disc was omitted from the analysis if,

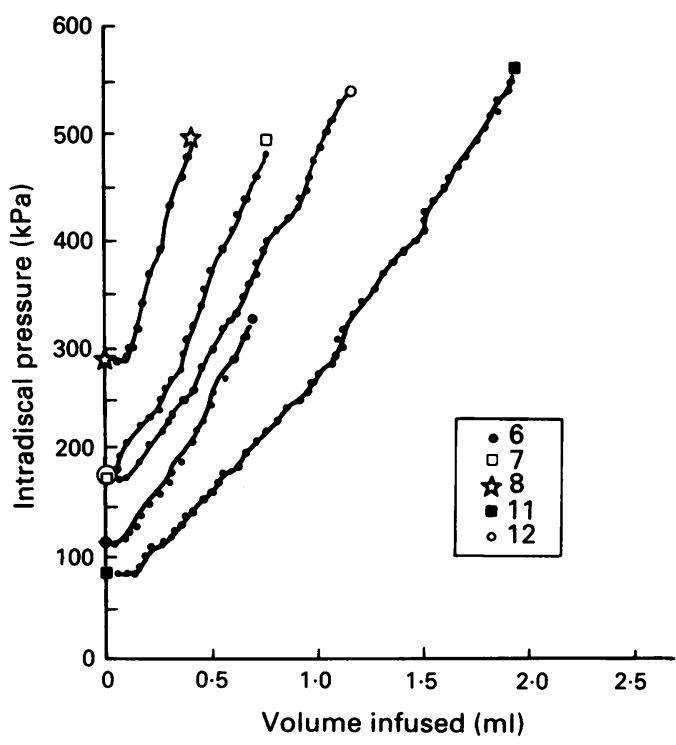

Figure 1 Effect on intradiscal pressure of a slow and continuous infusion of saline into the nucleus pulposus of five lumbar intervertebral discs from human cadavers (unloaded discs).

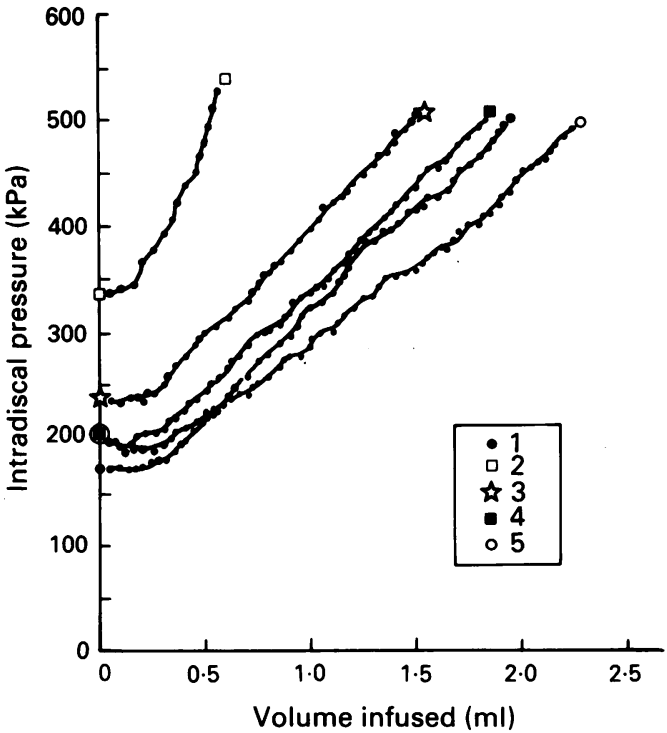

Figure 2 Effect on intradiscal pressure of a slow and continuous infusion of saline into the nucleus pulposus of five intervertebral discs that had been vertically loaded and clamped (loaded discs).

on sectioning it, saline was found to have leaked into the vertebral end plates or out of the annulus. The mean rate of pressure rise $/ \mathrm{ml}$ infused was $327 \mathrm{kPa} / \mathrm{ml}(2460 \mathrm{~mm} \mathrm{Hg} / \mathrm{ml})$.

The variation in rate of pressure rise $/ \mathrm{ml}$ infused varied threefold, and there was also a similar range of initial pressures. The correlation between initial pressure and rate of rise was poor $(r=0.37)$, however, indicating that initial pressure could explain only $13.6 \%$ of the pressure rise. There was no correlation between the class of disc and initial pressure $(r=-0.05)$. A better correlation was present between the pathological class of the disc and the rate of pressure rise $(r=-0.54)$ indicating that $28.7 \%$ of the rate of pressure rise could be inversely attributed to the class of disc.

LOADED DISCS

Results were similar for the configuration of the pressure rise in the five discs that had been preloaded at a fixed length before saline infusion (fig 2 and table 2). Although the linear correlation was high, there was a brief initial period of slow pressure rise. The rate of pressure rise was unexpectedly lower for the loaded discs, although this difference was not statistically significant ( $\mathrm{p}=0.08$, unpaired $t$ test). Comparison of initial pressure and class of disc for all 17 discs studied showed no correlation $(r=0 \cdot 04)$.

\section{Discussion}

There is much information on the characteristics of the human intervertebral disc, but a surprising lack of both clinical and experimental information on intradiscal pressures before any intervention. The best data in humans are probably from the studies of Quinnell $e t a l^{3}$ who used varying injection pressures in humans to estimate intradiscal pressure. They found initial lumbar intradiscal pressure in normal supine subjects to be 154 (SD 50) $\mathrm{kPa}$, a value similar to the 
present finding of 174 (SD 81) $\mathrm{kPa}$ in lumbar discs from cadavers. They also reported that their intradiscal pressure values were about 200 $\mathrm{kPa}$ less than those reported by Nachemson and Elfstrom, ${ }^{18}$ presumably the best previous information available. Quinnell $e t a l^{3}$ questioned the hydrostatic concept, based on their occasional findings of unilobar disc filling with contrast or a sudden breakthrough of fluid into a second lobe. The data presented here did not confirm these suggestions, because a slow, progressive rise was always found as saline was injected, as seen in the data from all the 10 discs illustrated here. These conflicting findings may well be due to the use of contrast for injection in the two previous studies; its high viscosity would prevent easy tissue diffusion. The use of saline, as reported here, should show the actual physiological relation more closely.

As noted earlier, there have been no previous organised attempts to determine compliance of the nucleus pulposus/annulus system through the pressure-volume relation. Previous studies, usually performed with contrast, have been limited to injection into the disc of a fixed volume with inadequate or no pressure recording, ${ }^{1}$ injection at a fixed pressure, ${ }^{2}$ or the anecdotal statement that it is difficult to inject more than 1 to $1.5 \mathrm{ml}$ into the lumbar disc. In the 17 studies reported here, an average of 21 pressure and volume points for each disc have been used. The results of the pressure-volume data are consistent and I believe that they represent the physiological response to intradiscal volume change.

Isolated nucleus pulposus tissue will undergo major changes in volume when subjected to altered electrolyte concentrations in the surrounding media. ${ }^{519}$ Whether similar changes occur in vivo is not known. If the intradiscal pressure is related to symptoms and signs of the low back syndrome in diseased discs, as many believe, ${ }^{20}$ then even slight physiological changes in intradiscal volume may be important. The mean rate of increase in intradiscal pressure during saline infusion in these studies was 327 $\mathrm{kPa}(2453 \mathrm{~mm} \mathrm{Hg}) / \mathrm{ml}$ increment in volume, and presumably the reverse should also be true. There are no data on physiological changes in disc volume in humans, except that Ranu concluded, from the viscoelastic behaviour of the spinal disc, that there is an overall increase in body height overnight, and as a result of this one has to adjust the car mirror in the morning. Also, in the absence of a gravitational effect, as the case in outer space, one would expect an increase in intervertebral disc volume. Therefore, there is a need to measure the changes in the intervertebral disc volume in humans both non-gravitational and on earth. ${ }^{21}$

Beneficial results have been reported in relieving the symptoms of a herniated disc with removal of disc tissue by chymopapain, ${ }^{6}$ percutaneous discectomy, ${ }^{78}$ and percutaneous laser vapourisation of nucleus pulposus tissue. ${ }^{9}{ }^{10} \mathrm{~A}$ recent editorial by Spengler ${ }^{22}$ concludes that there are no control data to support the use of percutaneous discectomy, and points out the value of traditional surgical discectomy and the beneficial response in treating musculoskeletal

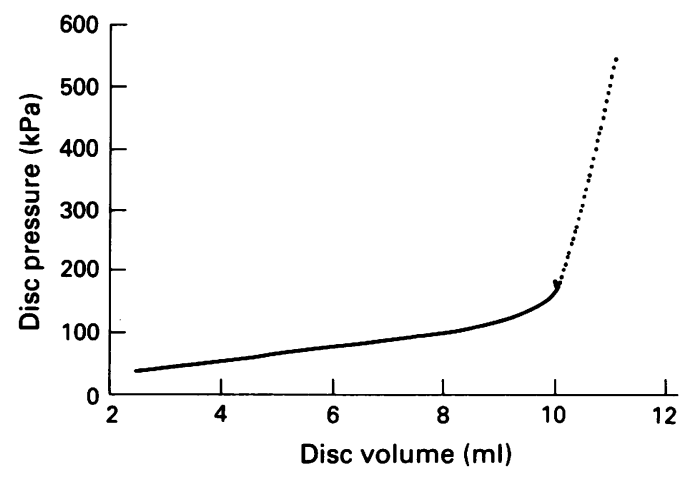

Figure 3 Experimental and conceptual representation of the pressure-volume relation in the human intervertebral disc. Initial volume of the nucleus pulposus was assumed to be $10.0 \mathrm{ml} .{ }^{23}$ Dotted line represents experimental data obtained during saline infusion. Solid line represents presumed pressure changes with volume (unloaded disc No 12).

complaints with diathermy. Such control studies are clearly needed. The data reported here, however, do provide a biomechanical basis for these procedures in that a major reduction in nucleus pulposus pressure should occur with removal of small amounts of nucleus pulposus tissue.

With a tight hydraulic system, I had expected to find an exponential pressure increase in pressure with volume increment, rather than the linear relation observed. My initial concept is supported if the pressure volume relation is expressed so as to include the entire volume of the nucleus pulposus, as seen in fig 3 , where an assumed initial nucleus pulposus volume of 10.0 $\mathrm{ml}$, calculated from the data of Hukins ${ }^{23}$ for human lumbar discs, has been used. The single points are experimental simultaneous pressure and volume data obtained during saline infusion in unloaded disc number 12. The solid line is a hypothetical extension of this relation to small volumes. This figure suggests that the data presented here, although linear, are actually on the linear portion of an exponentially rising pressure. It is also possible that physiological changes in nucleus pulposus volume will relate to nucleus pulposus pressure as shown here.

I thank Mr Peter Altman and Dr Robert Case for their assistance concerning this paper.

1 Brock $M$, Gorge $H$, Curio $\mathrm{G}$. Intradiscal pressure volume response: a methodological contribution to chemonucleoly response: a methodological contrib
sis. F Neurosurg 1984; 60: 1029-32.

2 Kambin P, Abda S, Kurpicki F. Intradiscal pressure and volume recording: evaluation of normal and abnormal cervical discs. Clin Orthop 1980; 146: 144-7.

3 Quinnell R C, Stockdale H R, Willis D S. Observations of pressures within normal discs within the lumbar spine. Spine 1983; 8: 166-9.

4 Merriam W F, Quinnell R C, Stockadale H R, Willis D S The effect of postural changes on the inferred pressures within the nucleus pulposus during lumbar discography. Spine 1984; 9: 405-8.

5 Charnley J. The imbibition of fluid as a cause of herniation of the nucleus pulposus. Lancet 1952; i: 124-7.

6 McCulloch J A. Chemonucleolysis: experience with 2000 cases. Clin Orthop 1980; 146: 128-35.

7 Kambin P, Sampson S. Posterolateral percutaneous suctionexcision of herniated intervertebral discs. Clin Orthop 1986; 207: $37-43$.

8 Maroon J C, Onik G. Percutaneous automated discectomy: new method for lumbar disc removal. $\mathcal{F}$ Neurosurg $1987 ; 66$; 143-6.

9 Choy D S J, Ascher P W, Liebler, et al. Percutaneous lase decompression of intervertebral disc. Laser Medicine and Surgery News and Advances. 1989; 7: 25. 
10 Ranu H S. The response of the human lumbar spinal discs to lasing. Proceedings of the First World Congress of Biomechanics. University of California, San Diego; August 30-September 4, 1990 b; La Jolla (CA). Vol. 1, 166.

11 Nachemson A. Lumbar intradiscal pressure: experimental studies on post-mortem material. Acta Orthop Scand 1960; (suppl 43): 1-104

12 Ranu H S. Relation between the nucleus and the annulus pressures of the lumbar spinal disc. Scand $\mathcal{F}$ Rheumatol
1986; suppl 60: 27 .

13 Ranu H S. Measurement of pressures in the nucleus and within the annulus of the human spinal disc due to extreme loading. Fournal of Engineering in Medicine. 1990; 204: 141-6.

14 Jayson $M$, Herbert $C$, Barks J. Intervertebral discs: nuclear morphology and bursting pressures. Ann Rheum Dis 1973 32: 308-15

15 Ranu H S, King A I. Correlation of intradiscal pressure with vertebral endplate pressure. In: Engineering aspects of the spine. London: Mechanical Engineering Publications, 1980: $37-42$.
16 Ranu H S. The distribution of stresses in the human lumbar spine. In: Yettram, A L, ed. Material properties and stress analysis in biomechanics. Manchester: Manchester University Press, 1989: 240-9.

17 Nachemson A. Disc pressure measurements. Spine 1981; 6: 93-7.

18 Nachemson A, Elfstrom G. Intravital dynamic pressure measurements in lumbar discs. Scand f Rehabl Med 1970; (suppl 1): $1-40$

19 Naylor A. Factors in the development of spinal stenosis syndrome. F Bone foint Surg [Br] 1979; 61: 303-6.

20 White A A, Panjab M M. Clinical biomechanics of the spine Philadelphia: Lippincott, 1990: 392.

21 Ranu H S. Time dependent response of the human intervertebral disc to loading. Engineering in Medicine 1985; 14 43-5.

22 Spengler D M. Percutaneous discectomy: where's the bee [editorial]. Fournal of Spinal Disorders. 1990; 3: 383

23 Hukins D W L. Disc structure and function. In: Gosh P, ed. Biology of the intervertebral disc. Vol 1. Boca Raton: CRC Press, 1989: 16. 